\title{
Visitor noise at a nesting colony alters the behavior of a coastal seabird
}

\author{
Rachel T. Buxton ${ }^{1, *}$, Reina Galvan ${ }^{1}$, Megan F. McKenna ${ }^{2}$, Cecilia L. White ${ }^{1}$, \\ Victoria Seher ${ }^{3}$
}

\begin{abstract}
${ }^{1}$ Department of Fish, Wildlife and Conservation Biology, Colorado State University, Fort Collins, Colorado 80523-1474, USA
${ }^{2}$ Natural Sounds and Night Skies Division, National Park Service, Fort Collins, Colorado 80525, USA

${ }^{3}$ Golden Gate National Recreation Area, Fort Mason, San Francisco, California 94123, USA
\end{abstract}

\begin{abstract}
Exposure to park visitors can disrupt animal behavior. Management strategies often aim to eliminate direct human disturbance; however, elevated visitor noise levels may remain. Coastal seabird colonies frequently overlap with scenic locations, resulting in high visitor noise and potentially altered behavior, habitat use, and fitness. We examine the impact of visitor noise on Brandt's cormorants Phalacrocorax penicillatus at Alcatraz Island, an important nesting site and one of California's most visited attractions. We used paired acoustic and video recorders to investigate the relationship between visitor noise levels and the behavior and relative abundance of cormorants in colonies adjacent to and far from a heavily visited building. Visitors were not visible from the cormorant colonies. At cormorant colonies adjacent to the visited building, disturbance-related behaviors increased with visitor noise. Conversely, there was no relationship between behavior and visitor noise in colonies far from the visited building. Cormorant disturbance behavior increased and abundance decreased when gulls were present at colonies adjacent to the visited building, whereas there was no relationship between gulls and behavior or abundance at colonies far from the visited building. Our results suggest that visitor noise alters cormorant behavior and decreases colony attendance, particularly in the presence of nest predating gulls. Visitor noise can be mitigated by implementing quiet zones, offering a cost-effective method of reducing disturbance to nesting cormorants. Understanding the relationship between altered behavior and demographic parameters is vital to conserving these coastal species and mitigating the effects from continued increases in recreation activity.
\end{abstract}

KEY WORDS: Anthropogenic noise - Behavior · Brandt's cormorant $\cdot$ Disturbance $\cdot$ Seabirds · Visitors

\section{INTRODUCTION}

Recreation in natural areas in the USA has increased rapidly over the past few decades, with $97 \%$ of the US population participating in some form of outdoor recreation each year and a record high of over 300 million national park visitors in 2015 (Cordell et al. 2002, National Park Service 2015). Increased coastal recreation has a range of ecological repercussions for protected areas, from physical disturbance (e.g. soil and vegetation trampling; Cole 2004) to

${ }^{*}$ Corresponding author: rachel.buxton@colostate.edu human presence displacing wildlife populations (Gabrielson \& Lincoln 1959, Stankowich \& Blumstein 2005, Steven et al. 2011). An emerging issue for wildlife in natural areas is the substantial levels of noise generated by high densities of visitor activity (Barber et al. 2010, Barber et al. 2011). Noise disrupts animals' ability to communicate and increases their perceived risk, resulting in changes in behavior, physiology, and distribution (Shannon et al. 2016b). Although coastal areas comprise only one-fifth of the land area of the contiguous US, they account for

() R.T.B. \& R.G. 2017. Open Access under Creative Commons by Attribution Licence. Use, distribution and reproduction are unrestricted. Authors and original publication must be credited. 
about half of all new recreational development (Marlowe 1999, Hall 2001). As the density and distribution of human activity continues to grow in coastal regions, it is important to understand the consequences of noise on local wildlife in order to manage the potential conflict between recreation and preservation goals in protected areas.

With over $25 \%$ of species listed as Threatened, seabirds are the most imperiled group of birds, interacting with humans at both ocean foraging grounds and terrestrial breeding colonies (Birdlife International 2008). Seabirds often nest in dense colonies and have long life-history strategies, with late ages at first breeding and low reproductive output, leaving them especially vulnerable to threats and slow to recover (Croxall et al. 2012, Buxton et al. 2014). Because coastal seabirds generally nest in scenic coastal environments, one of the most significant threats to these species is human disturbance, where colonies overlap with valuable tourist attractions (Yorio et al. 2001). Some seabird species become habituated to visitors (Nisbet 2000, Walker et al. 2006, Samia et al. 2015); yet for other species, disturbance from tourism can increase physiological stress response (Wilson et al. 1991, Ellenberg et al. 2007), alter behavior (Burger 1998), and increase nestling mortality (Watson et al. 2014), leading to decreased breeding success (Anderson \& Keith 1980). Visitor disturbance at seabird breeding colonies often results in fleeing behavior, increases in egg predation due to diminished nest protection (Kury \& Gochfeld 1975, Bolduc \& Guillemette 2003), or decreases in attendance and recruitment of prospectors (Finney et al. 2003).

Several methods have been developed to protect seabirds from disturbance at breeding colonies by minimizing visual disturbance, including restricting visitor approach using fence barriers (Ikuta \& Blumstein 2003), setback distances (Rodgers \& Smith 1995), and blinds (Shugart et al. 1981). However, the consequences of the remaining presence of noise have yet to be quantified. Evidence suggests that acute, high decibel sounds (65-85 dBA) impact seabirds (Brown 1990, Goudie \& Jones 2004), increasing rates of flushing; yet the impact of chronic noise is unknown. Noise can have subtle effects on animals - causing sensory degradation (masking acoustic cues from conspecifics or predators; Brumm \& Slabbekoorn 2005) or heightening perceived threat, resulting in heightened anti-predator response (predation risk hypothesis; Frid \& Dill 2002). In the latter case, by eliciting anti-predator behavior, noise may distract individuals from the attendance to more critical stimuli in the environment (distracted prey hypothesis; Chan et al. 2010, Chan \& Blumstein 2011) or noise may result in hypervigilance, where animals more readily flee from predators to avoid continued vigilance (flush early and avoid the rush hypothesis; Meillère et al. 2015, Shannon et al. 2016a). Thus, the impact of chronic noise may not manifest as an overt stress response, but rather as more subtle alterations in behavior and attendance, with potential long-term demographic consequences.

Coastal California is particularly rich coastal seabird habitat, where upwelling from the California Current System (CCS) results in one of the most productive marine ecosystems in the world (National Oceanic and Atmospheric Administration 2008). The Farallon Islands, off the coast of San Francisco, house the largest seabird colony in the continental USA (Ainley \& Boekelheide 1990). Warming trends and intense fisheries pressure have shifted the CCS ecosystem (Ainley \& Hyrenbach 2010), with longand short-term consequences for seabirds in this region (Sydeman et al. 2013). Coastal California is also the most populous region in the USA and is experiencing rapid development, increasing the potential interaction between humans, anthropogenic noise, and seabirds (Anderson \& Keith 1980). As the CCS continues to change, the overlap between humans and seabirds raises concerns about the sensitivity of nesting colonies to persistent noise disturbance and the potential for noise to exacerbate other anthropogenic stressors (e.g. incidental by-catch and competition with fisheries; Anderson et al. 2011, Cury et al. 2011).

Here we examine the effects of visitor noise levels on a colony of Brandt's cormorants Phalacrocorax penicillatus, a species considered to be particularly sensitive to human disturbance (Boekelheide et al. 1990). We examine the impact of visitor noise emanating from a building experiencing high visitation on Alcatraz Island, California, where visual disturbance from visitors was absent from the cormorant colony. Although Alcatraz Island is a heavily visited tourist attraction, it is an important breeding site for many species of seabird, including Brandt's cormorant. We used video and acoustic recorders paired with image recognition and acoustic analysis software to examine noise levels and estimate behavior and relative abundances of cormorants. We hypothesize that increased visitor noise in a building adjacent to the colony will result in altered behavior patterns and decreased relative abundance of cormorants. Moreover, we predict that disturbance due to visitor noise will be exacerbated by the presence of potential nest predators, western gulls. 

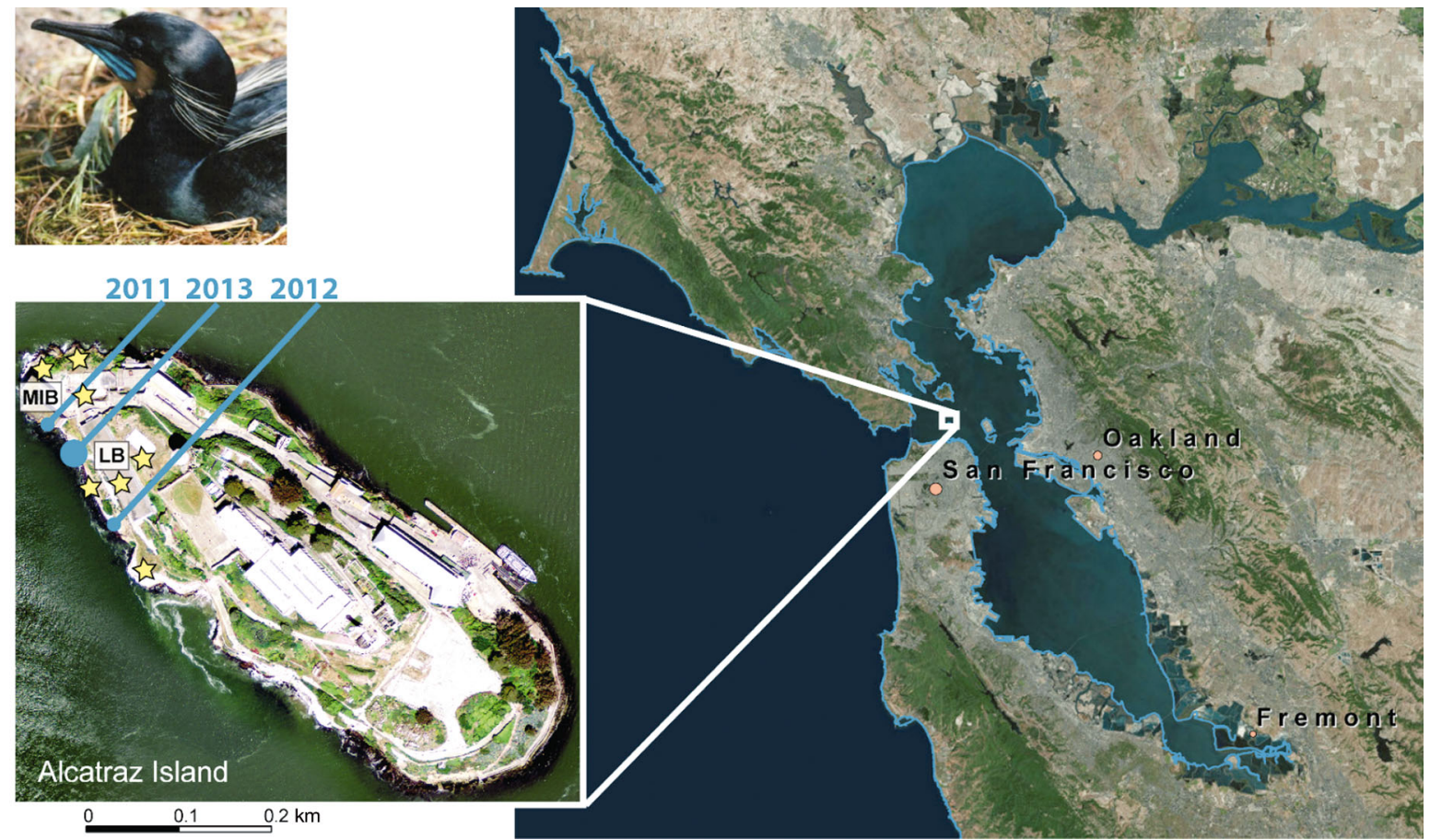

Fig. 1. Location of Brandt's cormorant (picture top left) study colonies (blue dots) from 2011 to 2013 adjacent to the Laundry Building (LB; visited) and south of the Model Industry Building (MIB; not visited) on Alcatraz Island in San Francisco Bay, CA, USA. Visitor access to the Model Industry Building is prohibited, while visitation levels increased in 2013 within the Laundry Building. Dot size is scaled to the size of the cormorant colony in each year. Yellow stars indicate the location of western gull colonies on the northwestern part of Alcatraz Island

\section{MATERIALS AND METHODS}

\section{Study site and species}

We examined the impact of noise on Brandt's cormorants Phalacrocorax penicillatus from 2011 to 2013 on Alcatraz Island, part of the Golden Gate National Recreation Area located in San Francisco Bay $\left(37^{\circ}\right.$ $49^{\prime} \mathrm{N}, 122^{\circ} 25^{\prime} \mathrm{W}$; Fig. 1). Alcatraz Island, managed by the National Park Service, is the most heavily visited tourist destination in Northern California, attracting over one million visitors annually (Robinson et al. 2013). Alcatraz is also a regionally important breeding site for seabirds, including Brandt's cormorants, pelagic cormorants Phalacrocorax pelagicus, western gulls Larus occidentalis, California gulls Larus californicus, and pigeon guillemots Cepphus columba, with ideal cliff-top breeding habitat. Notably, the Brandt's cormorant colony on Alcatraz is the only nesting site in San Francisco Bay, and the National Park Service aims to minimize the impact of humans on these birds (Thayer et al. 2000).

Brandt's cormorants are colonial nesting seabirds that inhabit inshore coastal waters associated with upwelling of the CCS (Wallace \& Wallace 1998).
Although variable, most birds begin to breed between the ages of 2-5 yr, with a mean clutch size of 3. Reproductive success and intermittent breeding depends on the abundance of fish, which is closely tied with the El Niño-Southern Oscillation (Elliott et al. 2016). The species' largest colony ( 9500 breeding pairs) is located about $50 \mathrm{~km}$ west of Alcatraz on Southeast Farallon Island. Brandt's cormorants are listed by the IUCN as Least Concern; however, populations are generally declining, threatened by commercial fishing, pollutants, declining forage fish, and disturbance associated with recreation (Wallace \& Wallace 1998, BirdLife International 2016b). Brandt's cormorant colony sizes on Alcatraz Island have fluctuated greatly since nesting began there in 1991: numbers peaked at 1782 breeding pairs in 2007, crashed to 0 pairs in 2009, and recovered to a total of 1030 pairs in 2013. On Alcatraz, Brandt's cormorant's main predators are western gulls, which depredate eggs and small chicks (Spear 1993). Western gulls nest at numerous sites on Alcatraz (Fig. 1), and breeding numbers were similar throughout the study duration (1004 breeding pairs in 2011, 998 pairs in 2012, and 1048 pairs in 2013; Robinson et al. 2013). 
We define Brandt's cormorant breeding periods based on mean reproductive phenology assessed at a subset of nests at each colony on Alcatraz Island in 2012 and 2013 (Table 1) (Paquin et al. 2012, Robinson et al. 2013): courtship was any date before egg laying, incubation was from egg laying to hatching, chick rearing was from hatching to crèching ( $25 \mathrm{~d}$ after hatching), and post-breeding was from $25 \mathrm{~d}$ after hatching to 30 September. Because no information was available for 2011, we used mean phenology from 2012 and 2013.

We focused on Brandt's cormorant breeding colonies on the western side of Alcatraz, adjacent to the Model Industry Building and the Laundry Building (Fig. 1). The Model Industry Building is closed to the public and thus the adjacent cormorant colony experiences little island-based noise disturbance. In 2011, the northern portion of the Laundry Building was opened to the public, with a capacity of 49 visitors (a maximum of 49 visitors allowed in the building at a time; Table 1). In 2012, visitor capacity increased to 150 , but the south end of the Laundry Building remained closed. In 2013, visitors were permitted in the entire Laundry Building and visitor capacity remained at 150 (Table 1). Visitor sounds in the Laundry Building were unusually loud due to high ceilings, concrete floors, and heavy metal doors. Rubber floor mats were designed to muffle footsteps, but resulted in loud squeaking from shoes. To prevent visual disturbance of visitors to nesting cormorants, barricades in the Laundry Building prevented access within $\sim 1 \mathrm{~m}$ from coastal-facing windows.

\section{Noise control and treatment}

In 2011 we collected video recordings at a cormorant colony of 43 breeding pairs adjacent to the nearby unused Model Industry Building (Fig. 1). In this year there were no cormorants breeding adjacent to the visited Laundry Building. In 2012 we collected video recordings at a colony of 46 breeding pairs that formed on the unused south side of the Laundry Building. Because focal colonies in 2011 and 2012 likely experienced minimal noise disturbance from visitors on the island, we combined these data and considered them a visitor 'noise control'.

In 2013, the year that visitor access was permitted in the entire Laundry Building, we collected video recordings at the colony adjacent to the Laundry Building, which was the largest on the island (365 breeding pairs, Table 1) (Robinson et al. 2013). Because the focal colony was directly adjacent to the visited building, we refer to the colony in 2013 as the 'noise treatment' and analyzed these data separately.

\section{Video analysis}

We obtained video recordings using a singlechannel mobile digital video recorder (MDVR25HR, Supercircuits) with a high-quality resolution of $640 \times$ 480 pixels at 5 frames $\mathrm{s}^{-1}$. The camera was placed adjacent to acoustic recorders within the Laundry Building and pointed out a window towards the cormorant colony. In 2011, when the cormorant colony

Table 1. Number of Brandt's cormorant Phalacrocorax penicillatus breeding in colonies monitored using video and audio recording adjacent to the Model Industry Building (MIB) and Laundry Building (LB) on Alcatraz Island, California. From 2011 to 2012 (control), no visitors were allowed in buildings adjacent to the monitored cormorant colonies. In 2013 (noise treatment), the building adjacent to the cormorant colony monitored allowed visitors access to all parts (north and south) of the building and increased visitor capacity

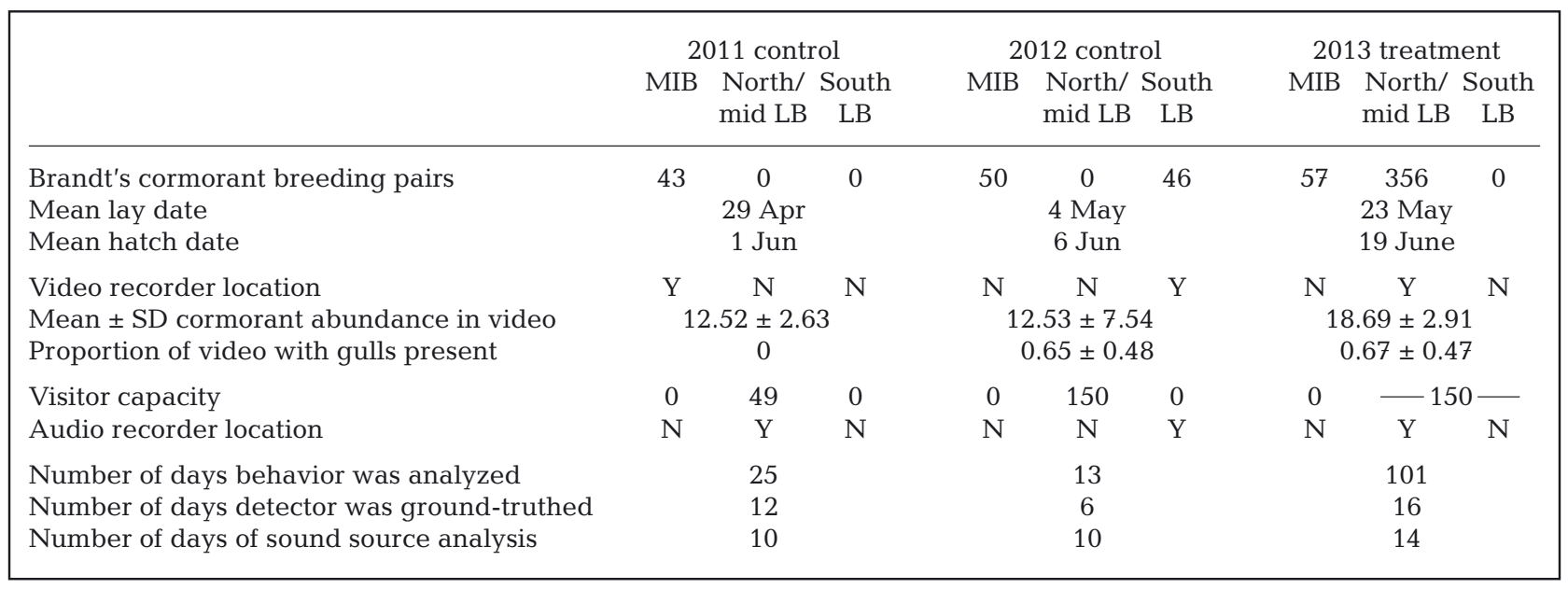


was not visible from the Laundry Building, the camera was placed inside the Model Industry Building pointed at the cliff-side colony. Each year, the camera was directed at a subset of the colony, capturing similar numbers of cormorants (Table 1 ; see Fig. S1 in Supplement 1 in the supplementary material at www. int-res.com/articles/suppl/m570p233_supp/).

\section{Behavior}

To examine cormorant behavior, we used VLC media player (version 2.2.4; VideoLAN, Paris, France) to watch a subset of camera footage. We only analyzed days with matching audio data and matching dates between years (Table 1). Within this time frame we analyzed footage every 20 min on every second day between 06:00 and 18:00 h Pacific Standard Time (PST). Because we had more data and noise was more likely to be affecting cormorants in 2013, we extended our analysis of 2013 video footage to include the entire breeding season (Table 1).

We determined the presence of 2 types of behaviors potentially related to disturbance (hereafter 'disturbance behaviors') within video recordings: wing fluttering and flying. These behaviors were selected based on previous literature (Bouton et al. 2005), where disturbance is known to cause flushing, resulting in birds taking flight (Boekelheide et al. 1990), and threat gestures, which includes fluffing, growling, and vigorous wing flapping (Wallace \& Wallace 1998). Threat displays are also used to prevent predation by western gulls (observed in response to gulls on Alcatraz; Feldman 1992, Robinson et al. 2013). Moreover, wing flapping may be associated with movement in the colony, where birds use their wings to balance when jumping and hopping. Behaviors were also selected based on preliminary observations of camera footage. We watched a subset of camera footage from each year when indoor noise levels (from acoustic recorders in the Laundry Building, see below) were high and low. Seemingly, wing fluttering, flying, and 'alert' standing behaviors were more frequently observed during high noise conditions. However, wing fluttering and flying were the only behaviors that could be identified reliably using footage from all 3 years (see Videos S1-S3 in the supplementary material). We define 'wing fluttering' as vigorous flapping of wings, rather than spread-wing posture typical of cormorants drying their plumage (Seller 1995), and 'flying' as birds observed taking off from the colony (see Videos S2 and S3).
At each 20 min interval, we watched $30 \mathrm{~s}$ of video footage, noting the presence of any cormorant within the colony taking off (flying), flapping its wings (wing fluttering), the presence of gulls (on the ground or flying over the colony), and image clarity (1: poor quality, 2: obstructed quality, 3 : high quality; see Videos S1-3).

\section{Relative abundance}

To count the number of cormorants within the camera frame, we developed and intended to use automated image detectors (MATLAB version 2015a, The MathWorks; see Supplement 1). To standardize the number of cormorants counted among years, detectors were constructed to identify cormorants within a delineated area of interest (subset of the camera frame; see Fig. S2 in Supplement 2). We ran the detector on the first 5 frames every 20 min for each day of video footage between 05:00 and 20:00 h PST. Only days with good conditions and matching audio and shared recording dates between all $3 \mathrm{yr}$ were analyzed (Table 1).

To ground-truth image detectors, we examined the first of each 5 frames. Within the area of interest we counted the actual number of cormorants and the number of cormorants identified by the detector. Within the entire image we noted the presence of gulls and image clarity. We found the number of cormorants identified by the automated image detectors of limited utility (see Table S2 and Fig. S3 in Supplement 2), thus we only used the actual number of cormorants counted in further analysis. Because we were unable to distinguish each bird's association with a nest, counts included all cormorants present within the detector's area of interest (Table 1; see Fig. S2).

\section{Audio analysis}

We obtained acoustic recordings inside the Laundry Building using an Edirol R-05 digital audio recorder (Roland Corporation) in 2011 and 2013 and an Olympus LS-7 recorder (Olympus America) in 2012. Recorders were mounted on a tripod adjacent to the window closest to the cormorant colony. Microphones were protected by foam windscreens. All audio data were collected in mp3 format at a sampling rate of $44.1 \mathrm{kHz}$. Audio data were then converted to calibrated 1-s 1/3 octave band sound pressure level (SPL) measurements from 12.5 to $6300 \mathrm{~Hz}$ (Mennitt \& Fristrup 2012). 
To quantify sound levels within the Laundry Building, we used the Acoustic Monitoring Toolbox software (AMT; developed by the National Park Service 2013). We calculated median broadband A-weighted SPL in decibels (dBA) for each 20 min interval. To ensure visitor noise was driving high SPL, we identified sound sources in a subset of recordings. We identified sound sources in $10 \mathrm{~s}$ of recordings each 2 min for 9-10 random days per year (within dates that overlapped among years; Table 1) using a combination of spectrogram visualization and listening to audio files in AMT. Sound sources were categorized as anthropogenic or natural; the former included aircraft, watercraft, maritime (e.g. fog horn), unknown, or visitors, and the latter included geological (e.g. wind, waves) or biological (birds). Visitor noises were more specifically categorized as voices, footsteps, phone ringing, music from exhibits, doors and other banging, and keys rattling. We calculated the probability of observing each sound source over each 20 min interval (hereafter 'audibility') by dividing the total number of events observed by 10 (the number of $10 \mathrm{~s}$ recordings scanned in $20 \mathrm{~min}$ ).

Finally, to ensure SPL at the cormorant colony was related to SPL in the adjacent building, we compared outdoor recordings collected in 2013 near the colony with those inside the Laundry Building. To collect outdoor recordings, we used an Edirol R-05 recorder with additional fuzzy-hat windscreens on microphones to minimize wind noise, and the same sampling specifications as above. We found that indoor and outdoor SPLs were closely related $\left(R^{2}=0.93\right.$, parameter estimate $95 \%$ confidence intervals = $0.12-0.35)$. Because indoor recordings were likely to be less affected by wind, we use indoor SPL in all further analyses.

\section{Quantitative analysis}

We used generalized linear mixed models (GLMM), or in the case of temporally autocorrelated data, generalized additive mixed models (GAMM), to assess whether noise levels explained cormorant behavior or relative abundance. We fitted 2 separate model sets, one set including 2011 and 2012 (noise control) data combined and one set with 2013 (noise treatment) data exclusively. Models were fitted in R version 3.2.2 with the libraries lme4 (Bates et al. 2012, $\mathrm{R}$ Core Team 2015) and mgcv (Wood 2006). In each model we included the following fixed effects: incubation and chick rearing as binary dummy variables (Hardy 1993), the presence or absence of gulls, me- dian SPL in the Laundry Building during the $20 \mathrm{~min}$ time period behavior was observed, the interaction between gull presence and SPL in the Laundry Building, and median SPL in the Laundry Building during the $20 \mathrm{~min}$ time period previous to the behavior observed. In all models we included hour of the day nested within date and image clarity as random factors. We examined autocorrelation between subsequent video observations using autocorrelation function (ACF) plots of model residuals. The final model structure was selected using a combination of the lowest Akaike information criterion (AIC) and the fewest number of autocorrelation values falling outside $95 \%$ confidence intervals (CI) on the ACF plot (i.e. reduced temporal autocorrelation of model residuals). To ensure parameter estimates would be comparable, all continuous fixed effects were scaled by subtracting the mean and dividing by one standard deviation (Schielzeth 2010).

Although we observed gulls in none of the video recordings examined in 2011, and 65 and $67 \%$ of recordings in 2012 and 2013 (Table 1), our results were unaffected whether data from 2011 and 2012 were analyzed together or separately (see Table S3 in Supplement 3). Thus, to increase the sample size of control data, we combined these years in all further analyses, while including year as a random factor.

We were unable to fit models with the full set of covariates for the presence of each behavior type separately (wing fluttering and flying), as models were over-parameterized and would not converge. Instead we converted the presence of any disturbance behavior to a binary response variable for further analysis. In an attempt to determine which behavior was most affected by SPL, we performed a preliminary analysis, fitting 2 GLMM sets with each behavior type as the response analyzed separately, where only a subset of fixed effects were included (gulls, median SPL during the 20 min time period behavior was observed, and the interaction between gulls and SPL). This resulted in 4 models - with either the presence of wing fluttering or flying as separate response variables, and including data during either the control (2011-2012) or noise treatment (2013) years (see Table S4 in Supplement 4). We then ran the full set of covariates on the presence of any disturbance behavior as a response variable. We found little evidence of autocorrelation among any behavior models, thus autocorrelation-moving average correlation structures were not included. All models had binomial error structure, log links, and Laplace approximations. 
Cormorant relative abundance models had Poisson error structure, log links, and Laplace approximations. We found significant temporal autocorrelation among GLMM model residuals, thus we included a simple first-order autoregressive correlation structure (one time lag) with hour nested within date as a grouping factor in a GAMM framework. Similar to the models above, we included hour of the day nested within date and image clarity as random factors by including ridge penalized smoothing terms. As abundance data were limited to the incubation and chick-rearing periods, we excluded the incubation dummy variable.

To examine the relationship between median SPL in the Laundry Building and the proportion of sounds from visitors versus other sources, we compared audibility and SPL using autoregressive linear mixed models. We fitted 4 separate models, with audibility of visitor sound, all anthropogenic sound, geological sound, and biological sound as fixed effects. In each model, median SPL in the Laundry Building was the response variable, year and the interaction between year and audibility of each sound source were included as fixed effects, and hour nested within date was included as a random effect. To control for temporal autocorrelation, we included a first-order autoregressive correlation structure with hour nested within date as a grouping factor.

In all cases we consider covariates with 95\% CI around parameter estimates that do not overlap 0 to indicate a strong effect.

\section{RESULTS}

Among years, we found that SPLs in the Laundry Building were strongly related to the audibility of visitor sounds and overall anthropogenic sounds (parameter estimate $\pm \mathrm{SE}=4.37 \pm 0.29$ and $2.24 \pm 0.29, \mathrm{R}^{2}$ $=0.95$ and 0.92 ; Table 2). The most frequently heard visitor sounds were voices and footsteps. There was no evidence that SPLs were related to audibility of geological or biological sounds; thus, hereafter we
Table 2. Parameter estimates $(\mathrm{PE} \pm \mathrm{SE}), 95 \%$ confidence intervals $(\mathrm{CI})$, and $\mathrm{R}^{2}$ tween the audibility of different categories of sound sources (model type) and suresure levels (measured in dBA) in the Laundry Building on Alcatraz 013, a Brandt's cormorant colony was directly adjacent to the LaunBuilding, which increased its visitor capacity, while in 2011-2012, cormorant colonies were further from the visited building and visitor capacity was restricted. Asterisks indicate parameter estimates whose confidence intervals do not bound 0 , indicating a strong effect

\begin{tabular}{|c|c|c|c|c|c|}
\hline Model type & Model parameter & $2.5 \% \mathrm{CI}$ & $97.5 \% \mathrm{CI}$ & $\mathrm{PE} \pm \mathrm{SE}$ & $\mathrm{R}^{2}$ \\
\hline Visitor sound & $\begin{array}{l}\text { Audibility* } \\
2011 \\
2012^{*} \\
2013^{*} \\
\text { Audibility } \times 2012^{*} \\
\text { Audibility } \times 2013^{*}\end{array}$ & $\begin{array}{r}4.41 \\
\mathrm{NA}^{\mathrm{a}} \\
-6.99 \\
1.48 \\
2.68 \\
1.75\end{array}$ & $\begin{array}{c}5.72 \\
-3.91 \\
4.31 \\
4.26 \\
3.3\end{array}$ & $\begin{array}{r}4.37 \pm 0.29 \\
-5.5 \pm 0.75 \\
2.87 \pm 0.69 \\
2.3 \pm 0.34 \\
3.04 \pm 0.35\end{array}$ & 0.95 \\
\hline $\begin{array}{l}\text { All anthropo- } \\
\text { genic sound }\end{array}$ & $\begin{array}{l}\text { Audibility* } \\
2011 \\
2012^{*} \\
2013^{*} \\
\text { Audibility } \times 2012^{*} \\
\text { Audibility } \times 2013^{*}\end{array}$ & $\begin{aligned} & 1.62 \\
& \mathrm{NA}^{\mathrm{a}} \\
&-9.06 \\
&-0.41 \\
& 2.14 \\
& 1.33\end{aligned}$ & $\begin{array}{r}2.84 \\
-5.32 \\
3.02 \\
3.65 \\
2.84\end{array}$ & $\begin{aligned} 2.24 & \pm 0.29 \\
-7.09 & \pm 0.9 \\
1.29 & \pm 0.83 \\
2.72 & \pm 0.36 \\
2.17 & \pm 0.36\end{aligned}$ & 0.92 \\
\hline $\begin{array}{l}\text { Geological } \\
\text { sound }\end{array}$ & $\begin{array}{l}\text { Audibility } \\
2011 \\
2012^{*} \\
2013^{*} \\
\text { Audibility } \times 2012^{*} \\
\text { Audibility } \times 2013^{*}\end{array}$ & $\begin{array}{r}-1 \\
\mathrm{NA}^{\mathrm{a}} \\
4.59 \\
3.77 \\
-12.54 \\
-4.03\end{array}$ & $\begin{array}{r}1.12 \\
8.06 \\
7.46 \\
-9.67 \\
-0.67\end{array}$ & $\begin{aligned}-0.16 & \pm 0.51 \\
6 & \pm 0.81 \\
5.69 & \pm 0.86 \\
-10.76 & \pm 0.69 \\
-2.36 & \pm 0.81\end{aligned}$ & 0.9 \\
\hline $\begin{array}{l}\text { Biological } \\
\text { sound }\end{array}$ & $\begin{array}{l}\text { Audibility } \\
2011 \\
2012^{*} \\
2013^{*} \\
\text { Audibility } \times 2012^{*} \\
\text { Audibility } \times 2013^{*}\end{array}$ & $\begin{array}{l}-1.66 \\
\mathrm{NA}^{\mathrm{a}} \\
3.08 \\
2.7 \\
-7.55 \\
-2.71\end{array}$ & $\begin{array}{r}0.08 \\
\\
6.94 \\
5.97 \\
-5.35 \\
-0.39\end{array}$ & $\begin{array}{r}-0.5 \pm 0.42 \\
4.55 \pm 0.92 \\
4.4 \pm 0.79 \\
-6.3 \pm 0.53 \\
-1.59 \pm 0.56\end{array}$ & 0.91 \\
\hline
\end{tabular}

refer to SPL in the Laundry Building as 'visitor noise' (Table 2).

\section{Behavior}

We examined Brandt's cormorant Phalacrocorax penicillatus behavior every $20 \mathrm{~min}$ for $25 \mathrm{~d}$ in 2011 (29 April-28 June 28), 11 d in 2012 (24 April-29 June), and 98 d in 2013 (24 April-29 September). We found wing fluttering or flying in $4.5 \%$ of video recordings examined in 2011, $11.7 \%$ of recordings in 2012 , and $18.4 \%$ of recordings in 2013 .

When all disturbance behaviors were combined into a single response variable, in the noise treatment year we found that disturbance behavior was less likely during the incubation period, more likely when gulls were present (Fig. 2), and more likely when visitor noise was high in the 20 min previous to observa- 
tion (Table 3, Fig. 3). During the noise treatment year, the proportion of time disturbance behavior was observed was highest when visitor noise was high during the chick-rearing period (Fig. 3). In contrast, in control years, when colonies were far from visitor noise, there was no significant effect of breeding period, gull presence, or visitor noise on disturbance behavior (Table 3). In control years we found only a positive interactive effect of visitor noise and gulls, where more disturbance behaviors were observed when visitor noise was low and gulls were absent (Table 3). When we split disturbance behaviors into flying and wing fluttering, we found that only wing fluttering behavior increased with visitor noise and the presence of gulls (see Table S4 in Supplement 4 ; Fig. 4). When visitor noise reached $>62 \mathrm{dBA}$ prior to observations during the chick-rearing period, cormorants were observed wing fluttering $\sim 35 \%$ of the time (Fig. 4).

We examined cormorant abundance every $20 \mathrm{~min}$ for $12 \mathrm{~d}$ in 2011 (8-17 June), 6 d in 2012 (24 May-29

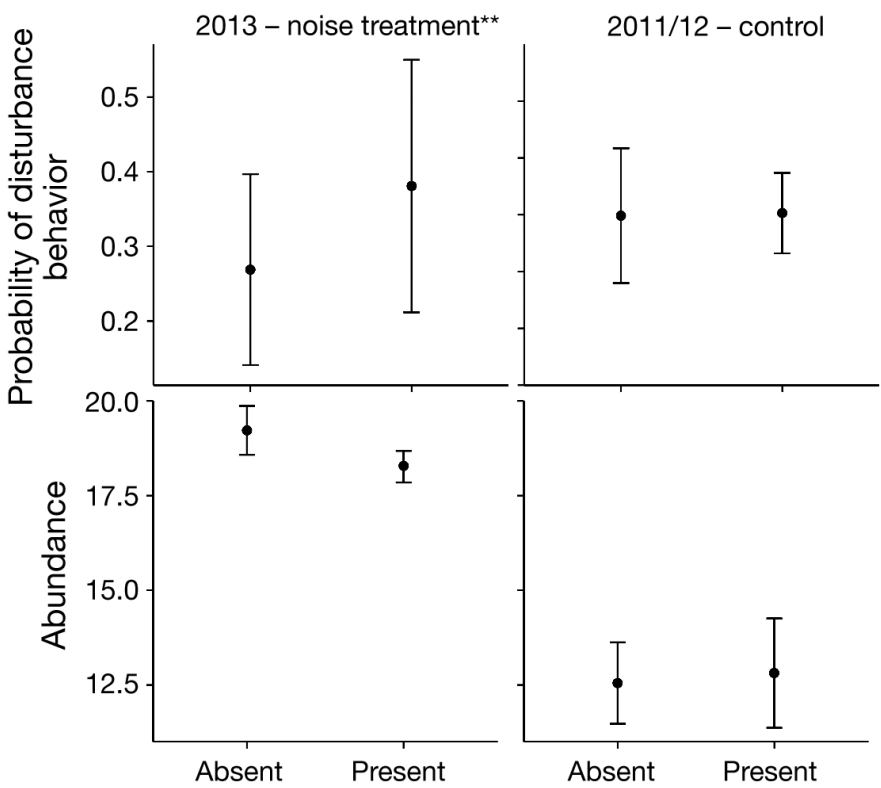

Fig. 2. Proportion of time Brandt's cormorant disturbance behaviors were observed (above) and cormorant abundance (below) in video recordings on Alcatraz Island, predicted using generalized linear and additive mixed models. Data are means \pm SE. Disturbance behaviors were higher and abundance was lower when gulls were present in video recordings in 2013 (when visitor noise was adjacent to the colony). There was no relationship between behavior or abundance and the presence of gulls in 2011-2012 (when visitor noise was far from the colony). Asterisks indicate that the 'presence of gull' parameter estimate did not overlap 0 , indicating a strong effect
June), and 16 d in 2013 (28 May-29 June). Although there were fewer cormorants when visitor noise was high in 2013, confidence intervals around parameter estimates bounded zero, indicating the effect was weak. In the noise treatment year, there were fewer

Table 3. Parameter estimates ( $\mathrm{PE} \pm \mathrm{SE}$ ) and $95 \%$ confidence intervals (CI) of generalized linear mixed models examining the relationship between proportion of Brandt's cormorant exhibiting disturbance behaviors (top) and cormorant abundance (bottom) with visitor noise at the time of observation (median $\mathrm{dBA}$ ), visitor noise previous to observation (previous median dBA), breeding period (post-breeding, chick rearing, and incubation), and the presence of gulls in video recordings on Alcatraz Island. In 2013, visitor noise (which drove higher SPL) was adjacent to the cormorant colony, while in 2011-2012, visitor noise was far from the colony. Asterisks indicate parameter estimates whose CI did not bound 0 , indicating a strong effect

\begin{tabular}{|c|c|c|c|}
\hline Parameter & $\begin{array}{c}2.5 \% \\
\text { CI }\end{array}$ & $\begin{array}{c}97.5 \% \\
\text { CI }\end{array}$ & $\mathrm{PE} \pm \mathrm{SE}$ \\
\hline \multicolumn{4}{|l|}{ Behavior } \\
\hline \multicolumn{4}{|l|}{2013} \\
\hline Intercept & -1.02 & -0.67 & $-0.85 \pm 0.09$ \\
\hline Post-breeding & \multicolumn{3}{|c|}{$\mathrm{NA}^{\mathrm{a}}$} \\
\hline Incubation* ${ }^{*}$ & -1.29 & -0.84 & $-1.06 \pm 0.11$ \\
\hline Gull presence* & 0.23 & 0.61 & $0.42 \pm 0.1$ \\
\hline Previous median dBA* ${ }^{*}$ & 0.02 & 0.26 & $0.14 \pm 0.06$ \\
\hline Gull presence $\times$ Median dBA & -0.02 & 0.31 & $0.15 \pm 0.08$ \\
\hline Median dBA & -0.2 & 0.1 & $-0.05 \pm 0.08$ \\
\hline Chick rearing & -0.3 & 0.22 & $-0.04 \pm 0.13$ \\
\hline \multicolumn{4}{|l|}{$2011-2012$} \\
\hline Intercept & -3.37 & -0.09 & $-2.18 \pm 0.61$ \\
\hline Incubation & \multicolumn{3}{|c|}{$\mathrm{NA}^{\mathrm{b}}$} \\
\hline Gull presence & -0.27 & 1.24 & $0.48 \pm 0.38$ \\
\hline Gull presence $\times$ Median dBA $*$ & 0.01 & 0.95 & $0.47 \pm 0.24$ \\
\hline Previous median dBA & -0.76 & 0.06 & $-0.35 \pm 0.2$ \\
\hline Median dBA & -0.63 & 0.11 & $-0.25 \pm 0.18$ \\
\hline Chick rearing & -0.52 & 0.35 & $-0.09 \pm 0.21$ \\
\hline \multicolumn{4}{|l|}{ Abundance } \\
\hline \multicolumn{4}{|l|}{2013} \\
\hline Intercept & 2.84 & 2.94 & $2.89 \pm 0.03$ \\
\hline Incubation & \multicolumn{3}{|c|}{$\mathrm{NA}^{\mathrm{b}}$} \\
\hline Chick rearing* ${ }^{*}$ & 0.06 & 0.24 & $0.15 \pm 0.05$ \\
\hline Gulls* & -0.08 & -0.01 & $-0.05 \pm 0.02$ \\
\hline Previous median dBA & -0.01 & 0.02 & $0.01 \pm 0.01$ \\
\hline Gull presence $\times$ Median dBA & -0.03 & 0.02 & $-0.01 \pm 0.01$ \\
\hline Median dBA & -0.01 & 0.01 & $0 \pm 0.01$ \\
\hline \multicolumn{4}{|l|}{$2011-2012$} \\
\hline Intercept & 2.81 & 3.7 & $3.26 \pm 0.23$ \\
\hline Incubation & \multicolumn{3}{|c|}{$\mathrm{NA}^{\mathrm{b}}$} \\
\hline Chick rearing & -0.27 & 0.42 & $0.08 \pm 0.18$ \\
\hline Gull presence & -0.11 & 0.24 & $0.06 \pm 0.09$ \\
\hline Previous median dBA & -0.11 & 0.01 & $-0.05 \pm 0.03$ \\
\hline Gull presence $\times$ Median dBA & -0.03 & 0.13 & $0.05 \pm 0.0$ \\
\hline Median dBA & -0.04 & 0.03 & $0 \pm 0.02$ \\
\hline \multicolumn{4}{|c|}{$\begin{array}{l}\text { aPost-breeding used as a reference category } \\
\text { b Observations in chick rearing and incubation only: } \\
\text { incubation used as a reference category }\end{array}$} \\
\hline
\end{tabular}




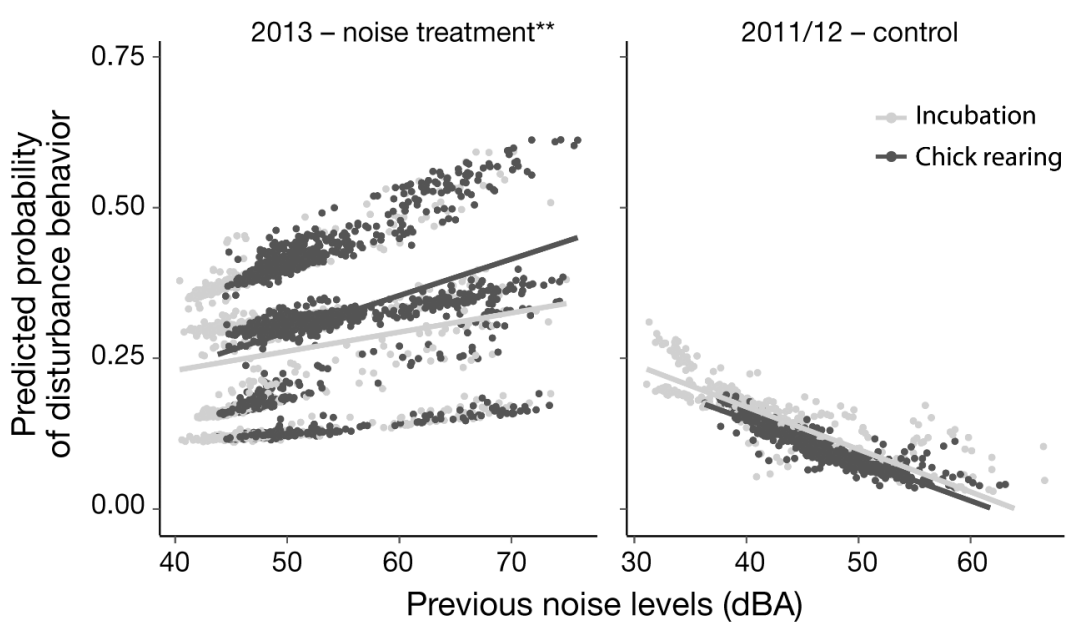

Fig. 3. Proportion of time Brandt's cormorant disturbance behaviors were observed with increasing sound pressure levels (SPLs; previous noise levels) on Alcatraz Island, predicted using generalized linear mixed models. In 2013, visitor noise (which drove higher SPL) was adjacent to the colony, while in 20112012, visitor noise was far from the colony. Previous noise levels represent the median SPL in the 20 time periods previous to the behavioral observation. Asterisks indicate that noise levels had a strong effect ( $95 \%$ confidence intervals around parameter estimates do not overlap 0)
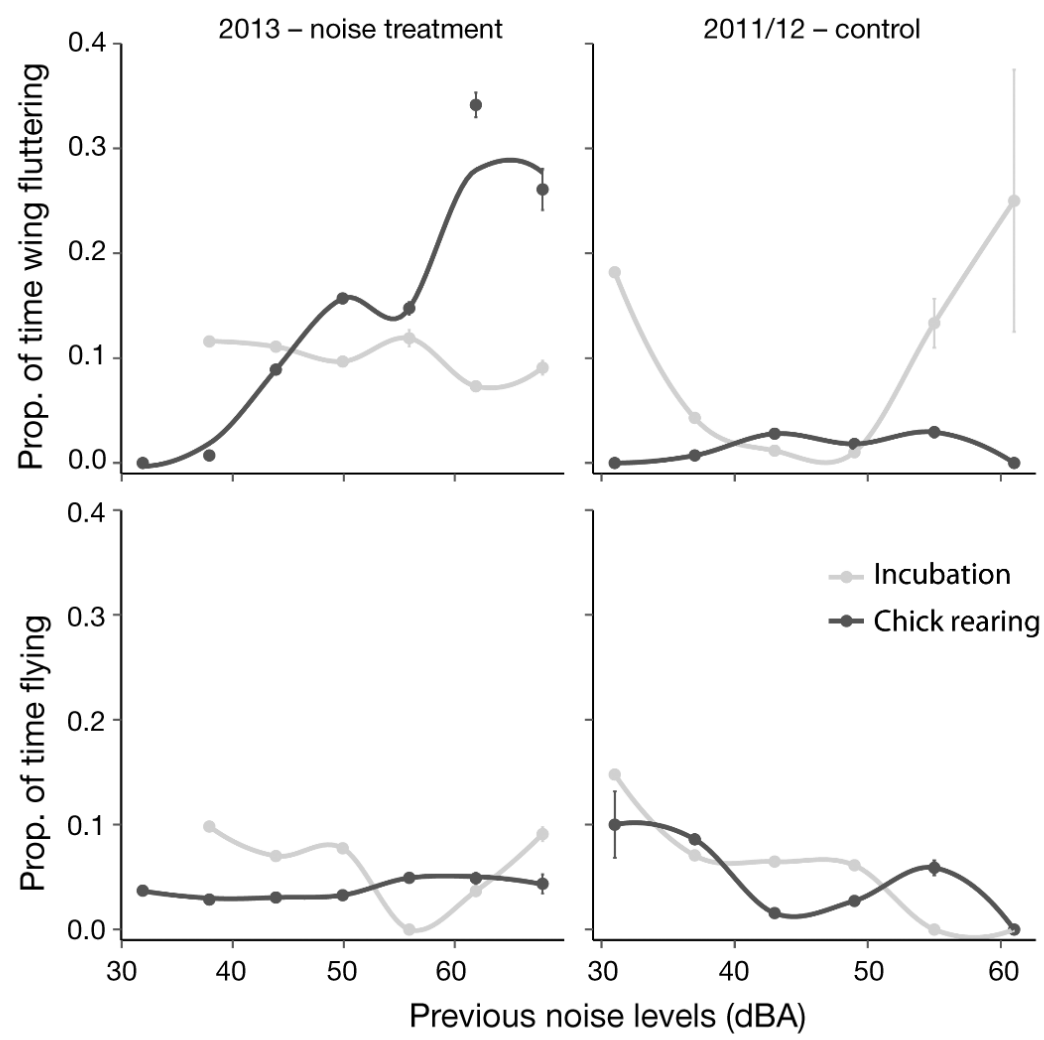

Fig. 4. Proportion of time Brandt's cormorant wing fluttering (above) and flying (below) behaviors were observed with increasing sound pressure levels (SPLs; previous noise levels) on Alcatraz Island. Data are means \pm SE. In 2013, visitor noise (which drove higher SPL) was adjacent to the colony, while in 20112012, visitor noise was far from the colony. Previous noise levels represent the median SPL in the 20 time periods previous to the behavioral observation cormorants when gulls were present, whereas in control years there was no relationship between cormorant abundance and gull presence (Table 3, Fig. 2). In other words, the presence of nearby visitor noise may be exacerbating cormorants' response to gulls. In control years, none of the covariates had significant effects on cormorant abundance (Table 3).

\section{DISCUSSION}

When visitor noise increased in the infrastructure adjacent to a Brandt's cormorant Phalacrocorax penicillatus colony on Alcatraz Island, cormorants increased disturbance-type behaviors. Increases in disturbance behavior were more likely during the chickrearing period and when gulls were present. We found no effect of visitor noise on cormorant abundance; however, fewer cormorants were observed when gulls were present in the year when the colony was adjacent to the noisy building. Our results suggest that noise from visitors alters the behavior of nesting Brandt's cormorants, and the interactive effect of visitors and gulls may decrease the number of birds attending a colony. We discuss a readily available, costeffective method to mitigate visitor noise disturbance on nesting cormorants and future directions of research into noise impacts on seabirds.

Brandt's cormorants and other pelecaniformes are particularly sensitive to human disturbance (Carney \& Sydeman 1999), which can cause higher rates of nest abandonment, flushing, and lower reproductive success (Anderson \& Keith 1980, DesGranges \& Reed 1981). Response to visitor noise is less understood. For waterbirds, visitor noise has been shown to alter foraging activity and behavior (Klein 1993, Burger \& Gochfeld 1998). For wildlife in general, exposure to anthropogenic noise ultimately affects the sensory modalities by which ani- 
mals interact with their environment, resulting in masking, distraction, and/or stress (Barber et al. 2010, Chan \& Blumstein 2011, Swaddle et al. 2015). Cormorant colonies are acoustically rich, and auditory systems mediate essential behaviors, such as predator avoidance, territory defense, and mating decisions (Williams 1942, Wallace \& Wallace 1998, Nelson \& Baird 2001). Our results were consistent with the theory that an increase in chronic, unfamiliar noise stimuli triggers increased surveillance, disturbance, or antipredator behavior, rather than causing abandonment (Francis \& Barber 2013, Shannon et al. 2014). We found that wing fluttering behavior increased following higher sound levels in a building adjacent to a colony; however, we found no evidence of flushing events. Vigorous wing fluttering is associated with movement in the colony and threat displays, used during disturbance events and to prevent predation events by western gulls (Feldman 1992, Wallace \& Wallace 1998). These results suggest that, instead of flushing, increased visitor noise adjacent to a cormorant colony increases the amount of time allocated to disturbance, and potentially, predator avoidance behavior.

We found that disturbance behavior following high sound levels was less prevalent during incubation and more likely in the chick-rearing period. In other species of cormorant, when chicks are disturbed they flee to nests furthest from the source of disturbance (Williams \& Cooper 1983, Shaw 1985). Because adults are less constrained by incubation requirements and chicks are mobile during the chick-rearing phase, birds may be more capable of exhibiting protective or disturbance-type behaviors when visitor noise levels are high. Moreover, the intensity of nest defense is thought to increase later in the nesting cycle, as the probability of nestling survival increases (Montgomerie \& Weatherhead 1988). Finally, visitor noise levels were higher during the chick-rearing period (June-August), which falls during peak visitation at Alcatraz Island (see Fig. S4 in Supplement 5).

The coastal habitat of Brandt's cormorants is naturally inundated with wave and wind noise, meaning that acoustic signals contend with environmental noise. In this context, an increase in sound energy from human sources can mask already constrained acoustic communication (Brumm 2013). In the years before breeding, young cormorants known as 'prospectors' visit nesting colonies to obtain information about habitat quality (Schjørring et al. 2000). For many colonial species, social information in the form of visual and acoustic conspecific cues is more important for habitat selection than the physical or structural properties of the habitat itself (Forbes \& Kaiser
1994, Danchin et al. 1998). Because of the importance of obtaining clear and reliable social information and the potential that visitor noise could mask acoustic cues, we predicted that increased visitor noise would reduce the abundance of cormorants by discouraging attendance by prospectors. However, we found no direct relationship between visitor noise and cormorant abundance. If prospectors are attending colonies regardless of whether visitor noise levels are high, this could result in (1) masking of important acoustic social information during times of high visitor noise (Slabbekoorn \& Ripmeester 2008), or (2) although noise does not cause prospectors to flee, it may signal riskier habitat, discouraging future recruitment (Frid \& Dill 2002).

We acknowledge that we were unable to distinguish prospectors from breeders in video recordings. Thus, future research aimed at disentangling the relationship between visitor noise and different age groups of cormorants should examine the response of prospecting and breeding birds to noise. Moreover, image detectors did not reliably identify the number of cormorants, due to rapidly changing light conditions and glare from the ocean. Although building an effective image recognizer was beyond the scope of our research, using algorithms to automatically identify the abundance of individuals across large numbers of photographs holds great promise for expanding the extent of video analysis (Kelly 2001, Speed et al. 2007, Groom et al. 2013).

We found a higher proportion of disturbance behaviors and lower abundance of cormorants when predatory western gulls were present in the year when the colony was adjacent to the noisy building. The different angle of video cameras between years may have affected the number of gulls visible around the colony (e.g. no gulls visible in 2011). Gull abundance was similar at colonies on Alcatraz among years (Robinson et al. 2013), the percentage of recordings with gulls present was similar in 2013 (noise treatment) and 2012 (control), and there was no relationship between cormorant abundance or disturbance behavior and gulls in the latter year, even when analyzed separately from 2011 (see Supplement 3). Thus, the lack of relationship between gulls and cormorant behavior and abundance when the colony was further from the noisy building is likely not a result of changing camera angle. Our results correspond with those of other colonial species, where higher noise levels increase perceived threat, and thus vigilance, resulting in increased rates of predator evasion in noisy conditions (Shannon et al. 2016a). A decrease in cormorant abundance with gull 
presence in noisy conditions fits with the 'flush early and avoid the rush' hypothesis, where animals flee soon after detection of a potential predator so as to limit the attentional costs of continued surveillance (Blumstein 2010, Samia et al. 2013). The breeding population of western gulls has increased in California and is currently 2-4 times larger than in the 1980s (BirdLife International 2016a, Hester et al. 2013). As in other large gull species (Larus spp.), it is thought that western gull populations will continue to increase due to anthropogenic food subsidies from fisheries discards and garbage dumps (Oro et al. 2013). Thus, the continued increase in recreation disturbance and gull numbers may have interactive effects on Brandt's cormorant behavior and abundance.

Relative to other forms of disturbance, visitor noise is both cheap and easy to manage. Simply posting signs asking visitors to be quiet has been shown to substantially reduce visitor noise in parks (Stack et al. 2011). Given the changes we observed in behavior and abundance with higher visitor noise levels, especially during the chick-rearing period, posting quiet signs during June and July would be an effective way of reducing cormorant disturbance. Managing other sources of noise, such as aircraft and boats, will likely be more challenging. Thus, in order to develop an effective noise management strategy for cormorants, future research should focus on the impacts of different types of noise (e.g. playback experiments) and the spatio-temporal dynamics of noise impact.

The long-term demographic repercussions of the altered cormorant behavior we observed here are unknown. Because animals have a limited behavioral budget, an increase in anti-predator behavior likely results in an increased energetic cost and decrease in other critical behaviors, such as parental care or foraging (Frid \& Dill 2002, Francis \& Barber 2013). In many cases, individual behaviors are closely related to demographic parameters (Wildermuth et al. 2013). Thus, subtle changes in behavior and activity during the breeding season may translate to impacts on reproductive success, which can have colony-level consequences for social species. In 2013, the colony adjacent to the noisy building (Laundry Building) had lower hatching success and productivity compared with the colony adjacent to the building where visitor access was restricted (Model Industry Building; Robinson et al. 2013). Productivity is highly variable amongst colonies on Alcatraz Island; thus, we are unsure whether the differences between these colonies are related to visitor noise.

Cormorants are less likely to return to a site to breed if they were unsuccessful and if adjacent nests were unsuccessful in the previous year (i.e. social information; Schjørring et al. 2000, Hénaux et al. 2007). Moreover, experience and familiarity of a nesting site is related to higher reproductive success, where knowing your neighbors decreases territorial aggression and knowledge of nearby feeding grounds makes foraging more efficient (Piper 2011). If noise disturbance causes lower reproductive success, cormorants may disperse to a new nesting site, or a colony may return to a disturbed site due to site fidelity, resulting in an ecological trap (Kokko \& Sutherland 2001). In contrast, some animals have behavioral flexibility, allowing them to offset the effects of disturbance and habituate to human stimulus (Nisbet 2000, Bejder et al. 2009). For example, within 10 wk, hoatzin Opisthocomus hoazin habituated to human approaches; however, birds exhibited heightened disturbance response to playback of tourist conversations throughout the experiment (Karp \& Root 2009). Thus, the effects of human disturbance vary depending on the type of stimulus and are dynamic over time and space (Weston \& Elgar 2007). Cormorant colony size and location are extremely dynamic on Alcatraz Island, where colonies fluctuate from less than 10 to more than 100 breeding pairs between years. Visitor noise levels are generally low when birds arrive at a colony and throughout courtship (see Fig. S4 in Supplement 5), which may not discourage settlement, but elevated noise during incubation and courtship may affect the probability of birds settling the following year. Future research examining how noise impacts colony dynamics and how changes in behavior translate to population-level consequences will be essential for adaptive management of coastal seabirds that overlap with heavily visited tourist destinations.

\section{CONCLUSIONS}

We found that the presence of visitor noise alone alters behavior patterns in nesting Brandt's cormorants, while noise and the presence of gulls reduced the abundance of birds attending a colony. Although the potential for conflict between humans and birds is already high, it is likely to intensify as coastal populations and outdoor recreation continue to increase. Moreover, human disturbance is only one of multiple threats faced by coastal seabirds (Croxall et al. 2012). As development and visitation increase in coastal areas, anthropogenic noise will become an increasingly pervasive threat, and noise mitigation is a viable option for protecting wildlife in protected areas. 
Acknowledgements. We thank J. Briggs and several National Park Service interns, including B. Prochazka, N. Gagnon, R. Earl, S. Sawtelle, and M. Nagarkar, for downloading data and maintaining equipment; and D. Joyce for equipment development and preparation. J. Thayer, B. Merkle, and L. Angeloni provided valuable support during project development, J. Job assisted with sound analysis, and three anonymous reviewers provided helpful comments to improve the manuscript.

\section{LITERATURE CITED}

Ainley D, Boekelheide RJ (1990) Seabirds of the Farallon Islands: ecology, dynamics, and structure of an upwellingsystem community. Stanford University Press, Stanford, CA

Ainley DG, Hyrenbach DK (2010) Top-down and bottom-up factors affecting seabird population trends in the California current system (1985-2006). Prog Oceanogr 84: $242-254$

Anderson DW, Keith JO (1980) The human influence on seabird nesting success: conservation implications. Biol Conserv 18:65-80

Anderson ORJ, Small CJ, Croxall JP, Dunn EK, Sullivan BJ, Yates O, Black A (2011) Global seabird bycatch in longline fisheries. Endang Species Res 14:91-106

Barber JR, Crooks KR, Fristrup KM (2010) The costs of chronic noise exposure for terrestrial organisms. Trends Ecol Evol 25:180-189

Barber J, Burdett C, Reed S, Warner K and others (2011) Anthropogenic noise exposure in protected natural areas: estimating the scale of ecological consequences. Landsc Ecol 26:1281-1295

Bates D, Maechler M, Bolker B (2012) lme4: linear mixedeffects models using S4 classes. R package version 1.1-6. http://CRAN.R-project.org/package=lme4

Bejder L, Samuels A, Whitehead H, Finn H, Allen S (2009) Impact assessment research: use and misuse of habituation, sensitisation and tolerance in describing wildlife responses to anthropogenic stimuli. Mar Ecol Prog Ser 395: $177-185$

Birdlife International (2008) State of the world's birds: indicators for our changing world. Birdlife International, Cambridge, UK, http://datazone.birdlife.org/userfiles/docs/ SOWB2008_en.pdf

* BirdLife International (2016a) Larus occidentalis. The IUCN Red List of Threatened Species 2016: e.T22694337A9344 9430. http://dx.doi.org/10.2305/IUCN.UK.2016-3.RLTS.T 22694337A93449430.en. Downloaded on September 2, 2016

BirdLife International (2016b) Phalacrocorax penicillatus. The IUCN Red List of Threatened Species 2016: e.T22696753A93584268. http://dx.doi.org/10.2305/IUCN. UK.2016-3.RLTS.T22696753A93584268.en. Downloaded on September 2, 2017

Blumstein DT (2010) Flush early and avoid the rush: a general rule of antipredator behavior? Behav Ecol 21:440-442

Boekelheide RJ, Ainley DJ, Morrel SH, Lewis TJ (1990) Brandt's cormorant. In: Ainley DJ, Boekelheide RJ (eds) Seabirds of the Farallon Islands: ecology, dynamics, and structure of an upwelling system community. Stanford University Press, Palo Alto, CA, p 163-195

Bolduc F, Guillemette M (2003) Human disturbance and nesting success of common eiders: interaction between visitors and gulls. Biol Conserv 110:77-83

* Bouton SN, Frederick PC, Rocha CD, Barbosa Dos Santos AT, Bouton TC (2005) Effects of tourist disturbance on wood stork nesting success and breeding behavior in the Brazilian Pantanal. Waterbirds 28:487-497

Brown AL (1990) Measuring the effect of aircraft noise on sea birds. Environ Int 16:587-592

Brumm H (2013) Animal communication and noise, Vol 2. Springer-Verlag, Berlin

* Brumm H, Slabbekoorn H (2005) Acoustic communication in noise. Adv Stud Behav 35:151-209

* Burger J (1998) Effects of motorboats and personal watercraft on flight behavior over a colony of common terns. Condor 100:528-534

* Burger J, Gochfeld M (1998) Effects of ecotourists on bird behaviour at Loxahatchee National Wildlife Refuge, Florida. Environ Conserv 25:13-21

*Buxton RT, Jones CJ, Moller H, Towns DR (2014) Drivers of seabird population recovery on New Zealand islands after predator eradication. Conserv Biol 28:333-344

Carney KM, Sydeman WJ (1999) A review of human disturbance effects on nesting colonial waterbirds. Waterbirds 22:68-79

Chan AAYH, Blumstein DT (2011) Attention, noise, and implications for wildlife conservation and management. Appl Anim Behav Sci 131:1-7

* Chan AAYH, Giraldo-Perez P, Smith S, Blumstein DT (2010) Anthropogenic noise affects risk assessment and attention: the distracted prey hypothesis. Biol Lett 6: 458-461

Cole DN (2004) Impacts of hiking and camping on soils and vegetation: a review. In: Buckley R (ed) Environmental impacts of ecotourism. CABI Publishing, New York, NY, p 41-60

* Cordell HK, Green GT, Betz CJ (2002) Recreation and the environment as cultural dimensions in contemporary American society. Leis Sci 24:13-41

Croxall JP, Butchart SHM, Lascelles B, Stattersfield AJ, Sullivan B, Symes A, Taylor P (2012) Seabird conservation status, threats and priority actions: a global assessment. Bird Conserv Int 22:1-34

* Cury PM, Boyd IL, Bonhommeau S, Anker-Nilssen T and others (2011) Global seabird response to forage fish depletion - one-third for the birds. Science 334:1703-1706

* Danchin E, Boulinier T, Massot M (1998) Conspecific reproductive success and breeding habitat selection: implications for the study of coloniality. Ecology 79:2415-2428

*DesGranges JL, Reed A (1981) Disturbance and control of selected colonies of double-crested cormorants in Quebec. Colon Waterbirds 4:12-19

*Ellenberg U, Setiawan AN, Cree A, Houston DM, Seddon PJ (2007) Elevated hormonal stress response and reduced reproductive output in yellow-eyed penguins exposed to unregulated tourism. Gen Comp Endocrinol 152:54-63

* Elliott ML, Schmidt AE, Acosta S, Bradley R and others (2016) Brandt's cormorant diet (1994-2012) indicates the importance of fall ocean conditions for northern anchovy in central California. Fish Oceanogr 25:515-528

Feldman JP (1992) Colony formation in Brandt's cormorants (Phalacrocorax penicillatus) on Southeast Farallon Island, California. MSc thesis, San Francisco State University, San Francisco, CA

* Finney SK, Harris MP, Keller LF, Elston DA, Monaghan P, Wanless S (2003) Reducing the density of breeding gulls influences the pattern of recruitment of immature Atlantic 
puffins Fratercula arctica to a breeding colony. J Appl Ecol 40:545-552

Forbes LS, Kaiser GW (1994) Habitat choice in breeding seabirds: when to cross the information barrier. Oikos 70 : 377-384

Francis C, Barber JR (2013) A framework for understanding noise impacts on wildlife: an urgent conservation priority. Front Ecol Environ 11:305-313

Frid A, Dill LM (2002) Human-caused disturbance stimuli as a form of predation risk. Conserv Ecol 6:1-11

Gabrielson IN, Lincoln FC (1959) The birds of Alaska. Stackpole Co., Harrisburg, PA, and Wildlife Management Institute, Washington, DC

Goudie R, Jones IL (2004) Dose-response relationships of harlequin duck behaviour to noise from low-level military jet over-flights in central Labrador. Environ Conserv 31:289-298

*Goom G, Stjernholm M, Nielsen RD, Fleetwood A, Peterson IK (2013) Remote sensing image data and automated analysis to describe marine bird distributions and abundances. Ecol Inform 14:2-8

* Hall CM (2001) Trends in ocean and coastal tourism: the end of the last frontier? Ocean Coast Manage 44:601-618

Hardy MA (1993) Regression with dummy variables. Quantitative applications in the social sciences. Sage, Newbury Park, CA

* Hénaux V, Bregnballe T, Lebreton JD (2007) Dispersal and recruitment during population growth in a colonial bird, the great cormorant Phalacrocorax carbo sinensis. J Avian Biol 38:44-57

Hester M, Carle R, Beck J, Calleri D (2013) Seabird conservation and habitat restoration: 2009-2012. Unpublished report to California Department of Parks and Recreation, Año Nuevo State Park

Ikuta LA, Blumstein DT (2003) Do fences protect birds from human disturbance? Biol Conserv 112:447-452

Karp DS, Root TL (2009) Sound the stressor: how hoatzins (Opisthocomus hoazin) react to ecotourist conversation. Biodivers Conserv 18:3733-3742

Kelly MJ (2001) Computer-aided photograph matching in studies using individual identification: an example from Serengeti cheetahs. J Mammal 82:440-449

Klein ML (1993) Waterbird behavioral responses to human disturbances. Wildl Soc Bull 21:31-39

Kokko H, Sutherland WJ (2001) Ecological traps in changing environments: ecological and evolutionary consequences of a behaviourally mediated Allee effect. Evol Ecol Res 3: 537-551

Kury CR, Gochfeld M (1975) Human interference and gull predation in cormorant colonies. Biol Conserv 8:23-34

Marlowe H (1999) Assessing the economic benefits of America's coastal regions. Trends and future challenges for US national ocean and coastal policy. American Coastal Coalition, Washington, DC

Meillère A, Brischoux F, Angelier F (2015) Impact of chronic noise exposure on antipredator behavior: an experiment in breeding house sparrows. Behav Ecol 26:569-577

Mennitt DJ, Fristrup KM (2012) Obtaining calibrated sound pressure levels from consumer digital audio recorders. Appl Acoust 73:1138-1145

Montgomerie RD, Weatherhead PJ (1988) Risks and rewards of nest defence by parent birds. Q Rev Biol 63:167-187

National Oceanic and Atmospheric Administration (2008) Biogeographic assessment off North/Central California, in support of revisions to sanctuary management plans for NOAA's Office of National Marine Sanctuaries. NOAA National Centers for Coastal Ocean Science (NCCOS), Silver Spring, MD

National Park Service (2013) Acoustical monitoring training manual. NPS, Natural Sounds and Night Skies Division. Fort Collins, Colorado. https://www.nps.gov/subjects/ sound/upload/NSNSDTrainingManual.pdf (accessed March 2015)

National Park Service (2015) Annual recreation visitation by park (1979 - Last Calendar Year). https://irma.nps. gov/Stats/SSRSReports/National\%20Reports/Annual\%20 Visitation \% 20By \% 20Park\% 20(1979\%20-\%20Last\% 20 Calendar\%20Year) (accessed June 2016)

Nelson JB, Baird PH (eds) (2001) Seabird communication and displays. CRC Press, Boca Raton, FL

Nisbet I (2000) Disturbance, habituation, and management of waterbird colonies. Waterbirds 23:312-332

* Oro D, Genovart M, Tavecchia G, Fowler MS, MartínezAbraín A (2013) Ecological and evolutionary implications of food subsidies from humans. Ecol Lett 16:1501-1514

Paquin A, Thayer J, Merkle W, Seher V (2012) Breeding ecology of Brandt's cormorants and western gulls on Alcatraz Island 2012: final report to the Golden Gate National Recreation Area (GGNRA), National Park Service (NPS). Farallon Institute, Petaluma, CA

* Piper WH (2011) Making habitat selection more 'familiar': a review. Behav Ecol Sociobiol 65:1329-1351

R Core Team (2015) R: a language and environment for statistical computing. R Foundation for Statistical Computing, Vienna. www.r-project.org

Robinson H, Thayer J, Merkle W, Seher V (2013) Breeding ecology of Brandt's cormorants and western gulls on Alcatraz Island 2013: final report to the Golden Gate National Recreation Area (GGNRA), National Park Service (NPS). Farallon Institute, Petaluma, CA

Rodgers JA, Smith HT (1995) Set-back distances to protect nesting bird colonies from human disturbance in Florida. Conserv Biol 9:89-99

* Samia DSM, Nomura F, Blumstein DT (2013) Do animals generally flush early and avoid the rush? A meta-analysis. Biol Lett 9:20130016

* Samia DSM, Nakagawa S, Nomura F, Rangel TF, Blumstein DT (2015) Increased tolerance to humans among disturbed wildlife. Nat Commun 6:8877

Schielzeth H (2010) Simple means to improve the interpretability of regression coefficients. Methods Ecol Evol 1:103-113

Schjørring S, Gregersen J, Bregnballe T (2000) Sex difference in criteria determining fidelity towards breeding sites in the great cormorant. J Anim Ecol 69:214-223

Seller RM (1995) Wing-spreading behaviour of the cormorant Phalacrocorax carbo. Ardea 83:27-36

* Shannon G, Angeloni LM, Wittemyer G, Fristrup KM, Crooks KR (2014) Road traffic noise modifies behaviour of a keystone species. Anim Behav 94:135-141

Shannon G, Crooks KR, Wittemyer G, Fristrup KM, Angeloni LM (2016a) Road noise causes earlier predator detection and flight response in a free-ranging mammal. Behav Ecol 27:1370-1375

* Shannon G, McKenna MF, Angeloni LM, Crooks KR and others (2016b) A synthesis of two decades of research documenting the effects of noise on wildlife. Biol Rev Camb Philos Soc 91:982-1005

Shaw P (1985) Brood reduction in the blue-eyed shag Phalacrocorax atriceps. Ibis 127:476-494 
Shugart GW, Fitch MA, Vern MS (1981) Minimizing investigator disturbance in observational studies of colonial birds: access to blinds through tunnels. Wilson Bull 93: 565-569

Slabbekoorn H, Ripmeester EAP (2008) Birdsong and anthropogenic noise: implications and applications for conservation. Mol Ecol 17:72-83

Spear LB (1993) Dynamics and effect of western gulls feeding in a colony of guillemots and Brandt's cormorants. J Anim Ecol 62:399-414

Speed CW, Meekan MG, Bradshaw CJ (2007) Spot the match - wildlife photo-identification using information theory. Front Zool 4:2

Stack DW, Peter N, Manning RE, Fristrup KM (2011) Reducing visitor noise levels at Muir Woods National Monument using experimental management. J Acoust Soc Am 129:1375-1380

Stankowich T, Blumstein DT (2005) Fear in animals: a metaanalysis and review of risk assessment. Proc Biol Sci 272: 2627-2634 [Biol]

Steven R, Pickering C, Guy Castley J (2011) A review of the impacts of nature based recreation on birds. J Environ Manage 92:2287-2294

Swaddle JP, Francis CD, Barber JR, Cooper CB and others (2015) A framework to assess evolutionary responses to anthropogenic light and sound. Trends Ecol Evol 30: $550-560$

Sydeman WJ, Santora JA, Thompson SA, Marinovic B, Lorenzo ED (2013) Increasing variance in North Pacific climate relates to unprecedented ecosystem variability off California. Glob Chang Biol 19:1662-1675

Thayer J, Harrald IE, Sydeman WJ, Hatch DA (2000) Baseline monitoring and assessment of effects of disturbance to seabird populations on Alcatraz Island, California, 1997-1999. Unpublished report to the National Park Service, Golden Gate National Recreation Area, United

Editorial responsibility: Kyle Elliott, Sainte-Anne-de-Bellevue, Québec, Canada
States Department of the Interior, and Point Reyes Bird Observatory, San Francisco, CA

Walker BG, Dee Boersma P, Wingfield JC (2006) Habituation of adult Magellanic penguins to human visitation as expressed through behavior and corticosterone secretion. Conserv Biol 20:146-154

*Wallace EA, Wallace GE (1998) Brandt's cormorant (Phalacrocorax penicillatus). In: Poole A (ed) The birds of North America online. Cornell Lab of Ornithology, Ithaca, NY. https://birdsna.org/Species-Account/bna/species/bracor (accessed July 18, 2016)

W Watson H, Bolton M, Monaghan P (2014) Out of sight but not out of harm's way: Human disturbance reduces reproductive success of a cavity-nesting seabird. Biol Conserv 174:127-133

Weston MA, Elgar MA (2007) Responses of incubating hooded plovers (Thinornis rubricollis) to disturbance. J Coast Res 23:569-576

Wildermuth RP, Anadón JD, Gerber LR (2013) Monitoring behavior: assessing population status with rapid behavioral assessment. Conserv Lett 6:86-97

Williams L (1942) Display and sexual behavior of the Brandt cormorant. Condor 44:85-104

Williams AJ, Cooper J (1983) The crowned cormorant: breeding biology, diet, and offspring-reduction strategy. Ostrich 54:213-219

* Wilson RP, Culik B, Danfeld R, Adelung D (1991) People in Antarctica - how much do Adélie penguins Pygoscelis adeliae care? Polar Biol 11:363-370

Wood SN (2006) Generalized additive models: an introduction with R. Chapman and Hall/CRC Press, Boca Raton, FL

Yorio P, Frere E, Gandini P, Schiavini A (2001) Tourism and recreation at seabird breeding sites in Patagonia, Argentina: current concerns and future prospects. Bird Conserv Int 11:231-245

Submitted: October 4, 2016; Accepted: January 31, 2017

Proofs received from author(s): April 9, 2017 